\title{
Theoretical Tensions Between Regulation, Governance, and Strategic Behaviour in a Federated World Order ${ }^{1}$
}

\author{
Dr. Emanuela Todeva, \\ University of Surrey, e.todeva@surrey.ac.uk
}

Purpose: This paper explores Kant's formulations on universal good will, perfect moral order, and universal peace, and that the world's citizenship should be organised in a federated system of states, free to choose their own universal laws.

Design and Methodology: This theoretical discussion is pursued in two separate sections. The first section reviews leading regulation theories that explain how governments in their decisionmaking capacity engage in regulation at macro-level of the entire socio-economic system. The second section follows from this argument and discusses the governance theory and alternative governance mechanisms designed and employed by governments to manage the strategic behaviour of the individual economic actors at mezzo- and micro-level of contract relationships.

Findings: This paper discusses some of the current theories that underpin the analysis and interpretation of public administration practice, or public governance in different socio-economic systems. We look at some of the dominant postulates of regulation and governance, and question to what extent they can be accepted as universal principles in line with Kant's argumentation. Different types of governance mechanisms are compared and contrasted in the context of strategic actors such as: the public government as a regulating authority, and the firms as regulated economic actors.

Originality and Value: The argument in this paper is that governments as regulators of national socio-economic systems are strategic actors in their capacity to actively shape the regulatory environment, implementing various coordination mechanisms that facilitate the functioning of the economy and the society. We attempt to make some ethical judgements on market imperfections and government imperfections in line with Kant's concept of universal moral order.

Keywords: Universal 'good will', federated world order, regulation, governance

Paper type: Conceptual paper

\footnotetext{
${ }^{1}$ In: International Journal of Social Economics, Special Edition on 'Kant Scholarship and the Economics of Governance and Regulation', 2010.
} 


\section{Introduction}

This paper explores one of Kant's formulations that the world's citizenship should be organised in a federated system of states, free to choose their own universal laws. Such a system assumes a universal peace, where there is no conflict of interests and a universal 'good will' that govern all members (Kant, 1795). Although Kant acknowledges that the citizens of autonomous states could choose an endless variety of laws and moral principles to govern their affairs, his metaphysical formulations confer the expectations that all governance systems should share a common universal Categorical Imperative (CI), or a set of moral principles that underlay the good will of all citizens and all states. Our discussion examines the possibility for such a universal system of governance and sources of variations in practice.

In a global world order there is a plurality of forms of organisation of different socio-economic systems. These forms of organisation refer to different structures of government and different sets of relationships between economic actors. The plurality itself stems from different social histories and national memories (path dependence), from different levels of industrialisation, economic development, and liberalisation of the market forces (economic determinism), and from different political systems and dominant cultural frameworks and political ideologies (political determinism).

The proliferation of different socio-economic systems has always been part of the human history. However, the visibility and interpretations of these variations has been subject to political recognition (particularly by dominant powers in the world), and theoretical recognition (by dominant paradigms in social sciences). The social and political sciences have failed so far to distil universal principles that establish the perfect moral order, according to Kant's formulation.

The plurality in governance and public administration has been established empirically in the literature. There is a vast body of social and political theories that explain individual systems.

Comparisons across systems are rare, and most of the established fundamental principles of societal organisation have been theoretically contested. One of these systems based on market economy with political democracy has been referred to as the most suitable to facilitate economic 
growth and wealth creation and to satisfy human needs, which in Kant's view are all imperfect motivations - far away from any moral principles advocating universal good for all. Critics to this system have been silenced with the argument that even though the market democracy is imperfect, it is the best invented so-far to serve humanity. In addition, there has been a deep conceptual rift in the theories that examine different parts of the system. While the literature on the economic part of the system puts emphasis on efficiency and growth through opportunity maximisation, the literature on the political part puts emphasis on the benefits of choice and majority rule, where none of these principles can be interpreted as a universal law for all in Kantian way.

This paper discusses some of the current theories that underpin the analysis and interpretation of public administration practice, or public governance in different socio-economic systems. We look at some of the dominant postulates of regulation and governance, and question to what extent they can be accepted as universal principles. Different types of governance mechanisms are compared and contrasted in the context of strategic actors such as: the public government as a regulating authority, and the firms as regulated economic actors. We look at both - the regulator and the regulated - as strategic actors making strategic choices under the information asymmetries that they generate. We look also at theories that explain the impact of public governance on the strategic behaviour of economic actors whose interests have been regulated.

While the economists still argue around the a priory notion of government - i.e. what is the nature of government and whether it should get involved in regulating markets (Krugman, 2009), the government is actively involved in a decision-making capacity that affects markets. Even when the government stands-back and let liberalised markets to determine the principles of economic transactions, the government is effectively governing these transactions by implementing policy choices. The rules in liberal markets are still legally binding and determined by the public authority.

The argument in this paper is that governments as regulators of national socio-economic systems are strategic actors in their capacity to actively shape the regulatory environment, implementing various coordination mechanisms that facilitate the functioning of the economy and the society. Hence, there is a strong asymmetry between those making the law and those following it. From 
that perspective, Kant's requirement for universality of principles (Kant, 1785) can not be fulfilled and we can only compare imperfect systems based on imperfect moral principles. We are pursuing a theoretical synthesis across public administration and economic governance theory that explain the role of government in its regulatory function, the governance mechanisms that are selected and implemented by governments, and the impact of these regulatory activities on the strategic choices of all other economic actors. Much of this discussion is based on assessment of the positive and negative implications from asymmetric experiences between governors and governed, where we attempt to make some ethical judgements on market imperfections and government imperfections.

This theoretical discussion is pursued in two separate sections. The first section reviews leading regulation theories that explain how governments in their decision-making capacity engage in regulation at macro-level of the entire socio-economic system. The second section follows from this argument and discusses the governance theory and alternative governance mechanisms designed and employed by governments to manage the strategic behaviour of the individual economic actors at mezzo- and micro-level of contract relationships. The paper concludes with some principles for comparative analysis of different public administration practices across a variety of socio-economic systems.

\section{Public Administration Theory and the Regulatory Function of the State}

The regulation of a socio-economic system requires a legitimate government that has authority and powers, as well as the capacity and capabilities, to generate the rules that govern economic behaviour within the system of their jurisdiction. Unfortunately Kant does not address the case when the social order is based on inequality, where some individuals can express their free will in designing laws, while others don't have this opportunity. Kant also does not provide guidance how to treat representation of the free will of human agents in a political context.

Natural boundaries of regulation systems are the national boundaries of countries, protected by national governments. International players, such as global corporations and multinational enterprises recognise when they hop-in and out of a system. In their operations, they adapt their strategies to different rules and practices, in different regulatory regimes, and build relationships 
with different public authorities. Hence, we have a heterogeneous system of players among which are national law-makers, national law-followers, international law-followers, and unequal distribution of power among these agents.

There is a shared view among many theoretical perspectives that public administration is simultaneously: a) governance of the society and economy within national boundaries; b) management of the resource allocation process; and c) institutionalisation of justice in the public domain, where public administrators are seen as agents carrying out the public interest with their authority (Wamsley, 1990, pp. 21-29). The leading public administration theories that aim to explain the functioning of public organisations, and the relationships that emerge in relation to the definition and fulfilment of public interests, are: the public choice theory; the social contract theory; and the principle-agent theory. These theories do represent the scientific knowledge of the regulation and governance of a socio-economic system. The inability of public administration theory to derive at a unified set of universal principles represents the state-of-art in social theory in general, where there is a proliferation of theoretical frameworks.

Kant does not provide much guidance towards universal principles that can be applied to a culturally embedded political relationships. His concept of the autonomous state derives from an individualistic point of view, where the state is constituted of autonomous individuals able to express their will. His concept of community is also quite simple, referring to reciprocal interactions and forces, guiding the co-existence of things and human actors (Kant, 1785). Such a view does not allow for any interpretation of institutions and private interests that are pursuit with no harm to, or to the detriment of others. Most of Kant's directions stem from his interpretations of reflexivity of human actors, or being able to understand and reason about causal relationships. It is very difficult to apply his moral principle of Categorical Imperative to the political domain, where the free will of human beings in practice is expressed through individual and institutional representation. All public administration theories however, recognise that there is a substantial difference between the individual choices of the represented (the public), and those of the representing (or individuals engaged in politics and government). 


\section{Public Choice Theory}

The public choice theory infers that the public chooses the type of the system of governance and mode of regulation. The theory advances the discussion on innovation support vs. bureaucratic authoritative allocation of resources, where it is assumed that bureaucratic government is based on hierarchy and command in regulation and decision making, while the innovation in government implies experimentation and the working of a 'free market' (Russell and Waste, 1998, McNutt (2002), Mueller (2003).

The choice, therefore, between a free market, and an administrative allocation of resources is a question of which means are more appropriate to certain chosen ends. As the purpose is universal and not questioned, the choice of the means (or the selection of a model of public administration) is justified - either with the efficiency argument (i.e. efficient markets), or with political and ideological choices (i.e. socialist government and public ownership of the means of production).

Critics of this juxtaposition emphasise that "the purpose of public organisation is the reduction of economic, social, and psychic suffering", and the enhancement of life opportunities for all societal members (LaPorte, 1971, p. 32). LaPorte's definition suggests universality of the purpose, where the institutional forms of achieving this purpose, or the implementation of the laws of duty may vary. This contrast is made with the assumption that both a bureaucratic and an innovative government are specific means-to-an-end, where the purpose and the socio-political objectives set by government have the transcendental power to frame all relationships in the socio-economic system.

The socialist system is an example of a public choice of a form of administrative co-ordination of macro-economic activities and relationships, along with the corresponding costs and benefits to society (Kornaj, 1992). Regulated vs. liberalised market economy is also a public choice that frames the role of government as a regulating authority. Both of these systems can be driven by a variety of practical objectives and moral principles, and neither of them suggests methods of implementation of the public choice, or the type of institutions designed to exercise the decisionmaking and resource allocation capacity of government. At the implementation level we can see that universal or moral principles break down even further to culturally and historically embedded 
practices, creating a proliferation of institutional adaptations and governance mechanisms that shape a specific national system of public administration (PA). Comparisons across national PA systems recognise that the political orientation of the government and the efficient coordination mechanisms employed by this government are distinctive but complementary choices.

\section{Social Contract Theory and Kantian Ethics}

The social contract theory reflects on the agreement between the public and the government as enacted through democratic elections. Government efficiency in fulfilment of the social contract is measured in terms of democratic accountability (Wilson, 1987). Transparency (or transcendental publicity - Kant, 1785) is proposed as the main guarantor for accountability, and the main solution to the problem of asymmetry of information between the governors and the governed.

Accountability and transparency are quite instrumental to functioning democracies. These, however, remain imperfect means for control of the law-makers by the law-followers. Kant does not give much insight on the control process. His Categorical Imperative assumes that rational human beings would follow the universal principles of moral duty and good will as an end-initself. Kant does not leave room for representation of the good will. There is a split agency into represented and representing, which raises the issues of transparency and accountability between the two.

The social contract theorists ignore the fact, that evaluation of both policy objectives, and outcomes is conducted mainly by the elected officials, therefore the public is not capable to exercise an affective control over government regarding the extent of fulfilment of the contract. The fact that the public through general elections could change government, does not mean that the public could evaluate the true outcomes from the work of this government. The theory of social contract does not make clear who is the agency of real control over the policy process. Public administrators never receive performance measurement (Selde, et.al., 1999), and their true accountability resides within the government hierarchy, and not within the public election system. In addition, compliance with government rules and regulations is much wider observed behaviour, rather then effective public control over decision making and justification for government rules and regulations. 
An uncontested ground for the social contract theory is the notion of reason and power in administrative action. It is the organisation theory, which looks at the individual, group, and organisational motives for certain decisions, choices and action. The implementation of the social contract therefore is subject to the motivations and enactments by different social actors, including government officials. Such behaviourist treatment of the notion of government is complemented by the institutionalism, which focuses on the rules and other institutional constructs that produce social norms and subsequent behaviours (Russell and Waste, 1998).

Institutions are necessary to change and maintain certain value preferences in a society. However, the very preferences, motivations and commitments are very often a subjective outcome of a cultural process of interpersonal interactions and a policy process of negotiations and bargaining, or what Kant refers to as imperfect reasons (1875). Neither behaviourism, nor institutionalism have developed definitions of preferences and choices that represent perfect intentions and good will. In fact, individual preferences and choices are defined as imperfect motivations in Kantian sense, or humans pursuing the satisfaction of their individual interests.

Humans are more motivated in environments where they have a greater choice but also a stronger control (Katzell and Thompson, 1990; Rainey, 1993). This empirical observation is counterintuitive to the social contract theory as it suggests that the public choice of government is conditioned by the government control itself.

Political objectives, institutional constraints, and individual motivations seem to be intertwined into a tight node that drives the continuous policy process in a socio-economic system. In this context, the social contract between the government and the public implicitly requires the support of an appropriate institutional framework, political leadership, and widely spread legitimacy of the administrative agencies. Issues of corruption of government and weak government are seen as deviations from the system, rather then as intrinsic systemic features that reflect the co-evolution of the economy and society. 
Every mission-driven government is established under a political leadership by a Party, and implies a top-down goal orientation and some form of planning and budgetary control of the resource allocation within the socio-economic system, where the implementation of the policy objectives is based on strict budget control over public finances. The efficiency of government is measured by the extent of achievement of the policy objectives, compared to the costs of policy implementation (including monitoring and control) - whether it is related to market regulation, or to direct intervention in the economy. This evaluation does not consider the moral grounds for these policy objectives. The implementation of political objectives involves not only allocation of resources, but building coalitions of agencies that bargain and negotiate between themselves certain outcomes. The political authority that shapes the regulatory environment, that subsequently affects individual and organisational behaviour, is the leading agency of change and reform in a society.

Social contracts, hence, are intermediated by a rich institutional canvas of political and other special interests groups, as well as monitoring and enforcement agencies. The socio-cultural environment simultaneously imposes frames of reference on all actors - the regulated and the regulators. The most universal principle that we can distil from this discussion, is that the regulation and governance of a socio-economic system is intermediated by institutions and the relationships between the government and the governed are subject to multiple subjective interpretations. Each actor in Kantian way makes unique judgements of the rules, agreements, and obligations to comply with these rules. Each human agent derives at his/her formulation of their duties based on these subjective interpretations. Ultimately, Kantian universal good will is enacted through imperfect motivations, shaped by imperfect institutions and negotiated contract agreements. Neither Kant's Categorical Imperative, not Social Contract theory can provide guidance for the role of institutions such as religious and political organisations, on shaping the subjective perception of duty and moral law.

Principle-agent theory is an extension to the behaviourism in public administration and advocates that the government is composed of elected officials as 'principles', and appointed administrators as 'agents'. Issues of accountability, communications and interactions between 'principles' and 'agents', as well as the role of political incentives and information asymmetries in decision 
making, are discussed within this theoretical perspective. Researchers are convinced that the policy choices of the 'principles' are 'framed' by the information provided by appointed and entrusted administrators (acting as agents), alongside with the bureaucratic discretion of the latter (Hill, 1985; Bendor, 1990; Selden, et. al., 1999). Authors conclude that change of policy direction by the 'principles' is constrained by the monitoring and control costs, associated with a particular structure of principle-agent relationships. The real representation of public interests appears to be driven by the bureaucratic 'agents', rather than the democratically elected 'principles' in government.

In this context, government failure could result either from systemic features that restrict accountability and transparency in the principle-agent relationship, or from some practices that have emerged at the implementation stage, and the interactions between elected and appointed government officials. Systemic failure, hence, can be attributed to either the political choice, or the administrative implementation of this choice, or to the cultural canvas of practices, moral judgements, and individual or institutional interactions.

\section{Kantian Dialectic}

Overall, the public administration theory distils some principles that stem from the heterogeneity of socio-economic actors. The distinction between 'principles and agents', and between 'governors and governed' opens a wide schism of rights, influence, and domination, where the conflict of interests frames an endless contest between different groups of actors. Although Kant's Categorical Imperative and the notion of moral law should apply to all human agents in a society, the heterogeneity of agents creates enclaves of special interests, attitudes, and groups of people that interpret differently the notion of duty.

The public administration theory is an eclectic theoretical field that has addressed a number of theoretical and empirical questions, related to the role of government in different socio-economic systems, the role of institutions and different regulatory activities in the administrative process, the variation in methods for manipulation and control of public opinion, decision making, or the political process itself. The issues of legitimacy and decline of authority, the nature of reforms led by government, and reforms in government, the costs and the benefits of the public administration 
to the society as a whole, and the impact of government regulatory activities on the economic behaviour of the governed, are in the focus of theoretical and empirical investigations.

Some of the empirical questions in public administration theory are related to difficulties in identifying clearly the leading institutions that represent the foundations of government, the agencies engaged in decision making and resource allocation within given institutional framework, and other stakeholders in a society that are affected by distributive decisions. There are also normative questions, related to the proper definition of the public interest, and the role prescribed to and played by the public agencies. Both types of questions are important in order to analyse the working of a social system. While the normative questions are related to political choices, the empirical questions derive from the implementation process, and focus on the actual working of government.

All questions regarding decision making in public administration have both empirical and normative aspect. There is uncritical acceptance of decisions as morally neutral and empirically self-evident. Organizational analysis employs the essentially technicist idea of decisions being totally divorced from the moral questions of the good. Decision-based analysis is usually trivialized, and questions of power and influence are neglected altogether (Harmon, 1998). This applies not only to generalised political decisions regarding the establishment of fundamental coordination mechanisms, but to specific administrative decisions on allocation of resources. Moral and ethical considerations on the distribution of outcomes to society are substituted with arguments for cost-efficiency. Rational decisions are, in this sense calculative decisions, rather then justified with Kant's Categorical Imperative for good will, or universal law that protect and represent the interest of all human actors (Kant, 1785).

In addition, administrative decisions involve substantial negotiations and a subsequent administrative control, and hence are in the realm of praxis, rather then in the realm of a priory knowledge. Kant does not give us much guidance on the translation of a priory knowledge to practice. He acknowledges that this takes place through the acting and choices of human agents, but the analysis remains individualistic and difficult to translate to social interactions in communities, where the ethical questions are more acute. 
Decisions by the public administrators can not be divorced from the process of decision-making, where interests are recognised, motives are enacted, and outcomes are negotiated. We can put a clear distinction between those that make the decisions (law-makers), and those that are subjected to the redistributive impact from these decisions (law-followers). Kant assumes that both can be guided by the Categorical Imperative of a universal good will. This, however, is not possible because decisions involve distribution of resources, which are material in nature and are unequally distributed in a society. Distribution of resources in heterogeneous systems of unequal human agents can not be universal and is determined by a political process that involves judgements on human needs and intellectual capabilities, assessment of value, and using preferences to overcome resource constraints. By their nature, decisions include negotiations and contestability. The legitimacy of the decision-making authority and the administrative capabilities of government officials to enact decisions are of critical importance.

The re-distributive power of decisions particularly in the context of limited resources, create inequalities, which become self-reinforced by the unequal access to these resources. The inequalities induce domination where Kant's universal principles can not be applied. Weber (1978) describes domination as the probability that certain specific commands will be obeyed by a given group of persons. Domination may be exercised at both stages of decision-making and decision implementation, or throughout the entire political process. Such domination requires moral and ethical solutions that differ from Kant's Categorical Imperative and have been explored at length in various political theories (the discussion of which goes beyond the scope of this work).

Another string of research in public administration research is lead by the historical question of the rise and decline of civilisations and the associated crisis in government. Daley's research (1998) revealed that the declines and revivals of the Roman Empire could be explained by the organizational legitimacy of the leading institutions, the ability of government to resist corruption, the organizational abilities to implement political decisions; and finally effective leadership of the policy process. Not one of these characteristics of government is associated with any moral or ethical criteria or universal principles. Only the ability of government to resist corruption can be interpreted as a high order Categorical Imperative, shaping the behaviour of government officials. 
Legitimacy and leadership are means-to-an end, and do not relate to any particular notion of duty and moral choices. The utilitarian approach in social sciences has shifted attention away from the ethics of human action, and has substituted moral questions with emphasise on efficiency and legitimacy. Both principles of efficiency and legitimacy represent a posteriory judgement, grounded in human experience and history. They are hence, principles that are politically justified by dominant political actors, and imperfect for a universal translation.

All four factors highlighted in Daley's research can be considered as essential means for effective regulatory activity by government. Governance and regulation of a socio-economic system require legitimacy, political leadership, organisational capacity and self-constraint from corruption and opportunism. The government as a regulator acts in a strategic way, through political choices, through design and implementation of policies, and through decisions that affect the strategic choices of the rest of the human actors in the system.

Administrative reforms, market oriented or otherwise, are not neutral. Changing the rules of the game by governments changes the probable winners and losers in political contests, and predetermines who would be disenfranchised in this process (Knott and Miller, 1987; Russell and Waste, 1998). Governments are the managers of a reform process, and their political choices preselect the outcomes from this reform process. Both the decisions and their implementation and negotiation are politically biased, and therefore not rational in Kantian way. Many social equity outcomes involve the distribution of benefits to those with few assets. Re-distributive decisions are often contested and require negotiation with some social groups. This process takes place in both market and centrally planned economies.

The public administration theory has acknowledged that the authoritative allocation of resources is central to human society (Russell and Waste, 1998). The costs of the public administration process however, can vary according to different implementation regimes, where different regulatory mechanisms and governance forms are adopted. Administrative costs can accumulate from: the efforts to negotiate and take political decisions; the monitoring and control of policy implementation; the costs of termination of policies, the costs of institution building and support, and the general costs of administration and management (Frantz, 1997, Greenwood, 1997). 
Rational agents in this context are those that can calculate and can minimise these costs - motives that carry no ethical value. Social systems utilise different co-ordination mechanisms in order to govern and regulate the allocation of resources. The theoretical discussion of these coordination mechanisms has taken place within the governance theory, and in particular, the economics debate on corporate governance and control, which will be discussed in the subsequent section of this paper.

\section{Governance and Co-ordination Mechanisms}

Overall public administration theory consists of postulates on the role and nature of government, and the variations in governance across different socio-economic systems. So how do governments govern socio-economic systems? What are the specific governing tools, and what is known in the literature as coordination and control mechanisms used by governments for managing economic transactions and socio-political interactions in different country contexts?

While regulation implies intervention activities at system level, governance, implies intervention at the level of individual economic actors. Governance involves design and implementation of incentives and constraints in order to manage the motives and strategic behaviour of actors. Economic governance is a system/mechanism for allocation of resources, control and coordination of economic activities at firm level that facilitates strategic direction, accountability, transparency and wealth creation (Todeva, 2005). Corporate governance is also known as an effective mechanism for allocation of resources in the economy and for creating value-added. The effectiveness of corporate governance depends on solving the agency problem of the separation of ownership from control and depends on clear allocation of ownership rights to some individuals, clear rules establishing rights and responsibilities, and compliance with these rules. It is not the autonomous will of human actors to follow these rules, but a requirement by law for compliance with these rules.

The universality of law is an attempt to bridge the gap between the governors and the governed. However, the two remain distinctively different. While the governors can express their free choice in Kantian way, the governed do not have this alternative, and hence their participation in self- 
coordination following some moral principles is constrained. Their action is driven by their will in compliance with rules designed by others and serving others' interests. Kant's free will is constraint by the fact that governance rules are not universal as they serve specific interests of a selected group of people in a society.

In order to untangle these tensions we will start with a general definition of co-ordination. According to Frances et.al. (1991) co-ordination implies the bringing into a relationship of otherwise disparate activities or events. Co-ordination therefore aims at making compatible the efforts of actors that are involved in co-operative or non-co-operative economic activities. Leading questions are who decides on the rules and regulations that establish the co-ordination mechanism, how this mechanism is implemented in a society, what range of activities are externally coordinated, and which activities are left under self-co-ordination? Here we would like to distinguish between external co-ordination, which implies agency, power, and politics, vs. self-co-ordination, which is an expression of the free choices of economic actors, and is interpreted as a spontaneously emergent agreements, rules and principles that facilitate impartial economic transactions between autonomous and free economic actors. In self-coordination economic actors enact self-constraints based on their relationships, values, and mutual agreements. The two forms of external governance and internal self-coordination may be congruent within a socio-economic system when one is an extension of the other.

Overall, there are three possible scenarios of coordination mechanisms in the literature - markets, hierarchies, and networks, or any combination between them (Levacic, 1991, Todeva. 1998). The design of these mechanisms is not the ultimate end of the policy and governance process as each of these mechanisms is a 'means-to-an-end', where the end is not specified. Each mechanism implies a different logic of co-ordination and leads to a variety of outcomes and costs. Each mechanism can be implemented by variety of rules and practices, which can lead to different sets of constraints on different groups of actors, and hence, limiting their options for free choices. Each mechanism is also interpreted through a different range of theoretical perspectives or theoretical lenses which constrain their comparative evaluation. Comparative research has suggested various typologies and extensions of coordination mechanisms (Todeva, 1998). 
In Coase's framework, firms (or hierarchies) and markets are considered as alternative means for organising similar kinds of transactions (Coase, 1937). While Williamson (1981) discusses the dichotomy between markets and hierarchies, Ouchi (1991) talks about the complementarity of markets, hierarchies and clans (or social networks). Kornai (1992) suggests five co-ordination mechanisms: 1) bureaucratic co-ordination, 2) co-ordination through markets, 3) self-governing co-ordination, 4) ethical co-ordination, and 5) family co-ordination. As an extension to this typology, Todeva (1998) discusses political co-ordination as a form that is typical for the socialist system of central planning. Ethical and family coordination are also interpreted as forms of network coordination. The subsequent sections of this paper discuss in turn these coordination mechanisms and their impact on the strategic behaviour and choices of economic actors.

Markets, hierarchies and networks remain at the heart of all coordination mechanisms, as they represent fundamentally different types of transactions and interactions. The concept of 'market' in general terms is defined as a co-ordination device that involves a voluntary exchange of goods and services between two parties at a known price (Levacic, 1991). Pro-marketers usually make a number of assumptions: regarding the existence of a homogeneous pools of buyers and suppliers, the transparency of information across the entire market space, the rational decision making on pricing and purchasing, the fairness and reciprocity in transactions, or the safeguards against opportunistic behaviour.

The functioning of the market requires by its very nature some form of regulation or organisation (i.e. hierarchy) at least to establish the minimum rules of self-regulation, and mechanisms for feedback and control. In global markets such as the financial sector, it is now empirically acknowledged that some form of regulation and oversight is essential to provide checks and safeguards for the system. Such regulation implies not only government and hierarchy, but also rules that affect the level of inequality between actors in a socio-economic system.

Pro-marketeers accept that markets are imperfect tools that require normative control by the state and a wider acknowledgement of the social embeddedness of economic value in the form of knowledge, social structures, dominance, politics, relationships, shared values, and other cultural factors (Todeva, 1998). However, the theoretical discussion of the economists stops short of 
recognition that behind demand stand social needs and social interpretations of these needs. Behind transactions stand social exchanges and relationships. The social canvas that embed market interactions is not universal, but vary for different actors and groups, and hence, the rules that govern socially embedded transactions can not be established as universal principles as always they will protect certain interests against others.

It is commonly recognised that markets on their own are not enough to provide for efficient transactions. When the transaction involves qualities that are not easily measurable, or when the exchanges involve long-term relationships and a vast complexity of goods, or uncertainty of payments, and markets fail to facilitate efficient transactions, other mechanisms such as hierarchies, alliance agreements, and strategic planning are put in operation

It is also important to stress that fast internationalisation of business activities and the globalisation of markets inevitably bring complexity of operations that bridge across extended inequalities. The examples of the complex global supplier networks in the telecommunications, the electronics, or the car manufacturing industry, and the lack of clear measurement of return on investment in R\&D in these industries, demonstrate that the positioning of businesses is driven much more by strategic intent and vision, rather than by performance outcomes and market incentives.

Most of the critical commentary here on the market coordination mechanism is based on the theoretical assumptions about market efficiencies. Such efficiencies in practice are realised by the complementarities between the market incentives and the regulatory administration that establishes the principles and rules governing economic behaviour, known as hierarchy.

The belief that markets and hierarchies are incompatible alternatives, is vigorously argued since Hayek (1944) who states that "both competition and central direction become poor and inefficient tools if they are incomplete, and a mixture of the two mechanisms means that neither will really work" (p. 31). The problem here is that no distinction is made between hierarchy and planning. While planning does ignore the question of agreements between economic agents on the objectives (Hayek, 1944), hierarchy or organisation is built upon agreements and contracts with specified roles and responsibilities. Mutual agreements and contracts do represent independent individual 
choices, which are the closest we could come the Kantian notion of a free will. It is argued that markets offer more choices to individuals to express their free will when there are no market imperfections.

The concepts of hierarchy and organisation exhibit the rationality in organisations through the establishment of formal rules, task specialisation, and coordination of activities. It is still believed that organisation represents the most efficient mechanism for coordination of activities of large groups of people who may have a variety of interests and preferences. Organisational hierarchy can be used effectively both as intra- and inter-firm mechanisms of structuring collective action.

If we look at the types of hierarchies (Todeva, 1998), they could be interpreted at the level of the firm, the level of an industry, or the level of the national and the global economy. Each micro, mezzo, and macro level refers to an internal organisational structure that can employ different types of relationships. At the micro-level, the intra-firm structure of authority and responsibilities can resemble an internal market (Mintzberg, 1983) for social and political transactions. Intra- and inter-industry production chains at a mezzo-level represent another organisational formation that is constituted by a number of inter-connected organisations and interconnected input and output markets. Market transactions at a macro-level require both individual firms to extend their internal administration, and the growth of external administration for contract enforcement by public institutions.

Hierarchy and organisation are the main instruments for states to exercise their regulatory function. A common practice in the literature on governance is the use of hierarchy and bureaucracy as overlapping terms to represent the public administration authority. The substitution of the notion of government co-ordination with bureaucratic co-ordination is also common. As a result of that, the dichotomy between government and market is replaced by the dichotomy of bureaucracy and market. The term bureaucracy usually is used in a sense of inefficient administration, rather than as a principle of rule-making and structuration of responsibilities, functions, power and authority. Both markets and governments can be inefficient. However, the substitution of the term government with hierarchy and bureaucracy induces assumptions of inherited inefficiency. In addition, planning can take place both in public organisations and in market institutions, as well as 
both from top-down and from bottom-up, which can involve substantial negotiations and complex contract arrangements between independent agents.

As Beetham (1987) states, in modern economies, due to the volume and complexity of transactions, the market has to be supplemented by two forms of hierarchy: one that is constituted within the market (the firms), and the other outside it (the government). The spontaneous division of labour at micro-, mezzo-, and macro-level induces co-ordination externally by the market, or internally by purposefully arranged specialisation and co-ordination of the division of labour by administrative means' (Beetham, 1987).

Hierarchy at a micro-level (within firms) is explained by Williamson (1985) as 'gains from allowing people to specialise according to their comparative advantage, or economising on resources. But the very existence of a specialisation induces inequality in the distribution of power and influence, and therefore raises the costs of internal negotiations and bargaining over allocative decisions. Specialisation within firms also is seen to create monopoly over certain decisions (McGuinness, 1991). Specialisation and division of labour induces structural inequalities that constrain the free choices of actors and generate structural privileges to some at the expense of others.

It is important to note that both market failure and government failure are associated with their deficiency to co-ordinate highly complex economic transactions. Both co-ordination mechanisms cannot prevent concentrations of power by a limited number of actors, and both can generate inequalities and structural rigidities.

In Todeva (1998) we argued for the complementarity of markets and hierarchies as coordination mechanisms, recognising that both represent imperfect tools for allocation of resources and regulation of economic activities. Both generate inequalities which create political tensions and have unaddressed ethical consequences. Network coordination is proposed to address these deficiencies and to create an environment where autonomous actors make choices, build relationships, and sign agreements that create rules for the coordination of collective action. 
Markets and hierarchies as coordination mechanisms are associated with the mainstream (corporate) governance theory that looks at the distribution of ownership rights between the public and the private sector, and at the consequences from the separation of ownership and control, or the distribution of coordination and control across multiple agents. Networks represent these messy arrangements where there are no clear ownership boundaries and the control is distributed across multiple actors.

Relational (or network) governance as a concept is discussed in a field that aims to disentangle the horizontal and vertical relationships that emerge in the process of coordination of decision making and resource flows in complex socio-economic systems. The network coordination mechanism is implemented to establish some common rules and practices of decision-making, and resource allocation in the context of distributed control rights and responsibilities and among loosely connected agents. Network coordination emerges when interconnected actors start to coordinate present undertakings, and establish agreements for future activities.

Governance mechanisms that are based on interactions and relationships are also known as 'collaborative governance'. Collaborative governance demonstrates an alternative way for realignment of interests of all economic actors. Collaborative governance facilitates information sharing, learning and innovation that ultimately brings comparative advantage to firms. Examples of collaborative governance are the Japanese corporate groups 'keiretsu' and 'sogo-shosha' (Todeva, 2006), various conglomerates and multinational corporations, or other smaller scale community and family businesses based on shared decision making. The main advantages of these formations are: their flexibility, adaptability, facilitated information and knowledge exchange, access to a range of alternative sources of financial assistance, and collaborative attitude to problem solving.

Networks are seen as clusters of large firms charging each other mutually beneficial prices (Todeva, 2005), while collectively extracting other market benefits through a collective action for maximising the joint welfare of all member firms (Lincoln et al., 1996). Overall, the literature on network coordination promotes the idea of superiority of relational alignment of interests against the ideas of adversarial market coordination, or the political bureaucratic coordination (Todeva, 
1998). In this literature there is some discussion on corporate networks, family and community networks and the specific mechanisms used for their coordination and control. The discussion on family business networks is primarily in the context of Chinese business networks, quanxi, and kin relationships that translate into economic activities with shared assets, liabilities, profits and rents. Under this umbrella can be qualified various donor / recipient relationships, mutual assistance practices, voluntary work for the community, friends helping to substitute for market exchanges and services, or other family support activities ranging from house-keeping to business assistance. Employing relatives or friends is still a practice in situations that require trust, loyalty, or some extraordinary efforts. Research on the effectiveness of such methods is still lacking in the literature.

\section{Conclusions}

None of the mechanisms discussed in this paper in the previous section, however, can establish claims for universality or fairness, to satisfy Kant's requirements for a Categorical Imperative that establishes a universal moral order. The regulation of choices by strategic actors bares the inherited heterogeneity of their interests, intent and will. Kant's Federated World Order has to be constituted from self-interested rational and calculative actors and regulated inequalities, rather then by universal laws and independent actors bounded by their intrinsically good will and moral choices (Kant, 1788).

Most of the regulation and governance theorising has been informed by political ideologies and / or empirical observations. It remains in the domain of our contested practical knowledge of political systems and government interventions in the society. Both governance and regulation theories still do not offer a wider platform for comparisons across different socio-economic systems. Political economists or public administration theorists have developed various positivist arguments that exploit concepts such as: efficiency, interests, and mechanisms of control-applied to the regulation of national systems and the governance of economic activities within them. Definitions of these concepts vary, and they are employed at different level of abstraction. Although there are some theories that have attracted more attention then others, none of them offer 
a set of universal principles for comparative analysis, or as a humanistic platform for ethical governance and in a Federated World Order..

Each socio-economic system, such as capitalist, socialist, or a developing economy, is conceptualised using different frame of reference. For the analysis of the capitalist system, the focus is put on incentives, constraints, and efficient market forces. The socialist system is discussed in terms of effectiveness of government intervention in the allocation of resources for public good. A developing economy usually is discussed in terms of the strengths / weaknesses of the institutional environment and the relationships between the public and the private sector and how both contribute to economic growth and wealth creation. Global comparisons reveal that any socio-economic system has aspects of active market forces, government interventions, specific institutional environment, and a particular dynamics between the public and the private sector. In a globalised world it is essential to establish some practical definitions that can allow comparisons across all these areas, and their multi-level interactions.

We have attempted to synthesise across multiple theoretical arguments offering a view that complex socio-economic systems require complex instruments of government, and that the effectiveness of government should be judged by the final outcomes from the regulatory activities by the state, including living standards, economic development, and wealth creation and distribution of socio-economic benefits. Different situations of economic development require different government policies and the implementation of different coordination and control mechanisms. There are no universal principles of regulatory practice. In a global world order it is expected that there will be a proliferation of different administrative practices at macro and micro level.

At micro-level our argument in this paper is that for firms to operate in a market environment, appropriate hierarchical co-ordination is required in order to provide information and communication infrastructure, which then becomes endogenous to firm's decision making. A form of organisation is an essential element of any coordination mechanism that affects strategic behaviour with implications for wealth creation. Any organisational arrangements, however, 
constrain the individual autonomy, which is essential to Kant's transcendental idealism (Alison, 1986).

In this paper we have argued that rational economic actors are combining in practice different coordination mechanisms and different principles that govern their interactions, exchanges, and participation in the socio-political process. The inefficiency of organisational structures are preferred by the firm's decision makers in the cases of relatively greater costs of open market transactions, or in the cases of high risks and uncertainty, environmental threats, and unpredictability of the outcomes. This view is very well pictured by Richardson (1972) who describes firms as 'islands of planned co-ordination in a sea of market relations'. In addition, both cases of internalisation or externalisation of activities require some form of coordination and control, or a form of governance and administration - either at a micro level, or at a macro-level.

Government intervention at a macro level is a feature of any market economy. The proper functioning of the market, according to Harvey (1996), is a result of a systematic political process that involves government intervention through taxation, subsidies, international relations between government, or regulations in the context of a complex and contested international arena.

The classical price mechanism of efficient markets is 'tuned' by governments. Even in liberalised economies, where prices are determined by the firms themselves, and reflect real demand, government taxation or inter-firm relationships with buyers and suppliers, play a critical role. Privileged information on potential demand, or powerful lobbying of governments for specific taxation policies, could make a significant impact on prices. The price mechanism in distorted markets is far from an efficient signal between actors, and is totally inadequate to improve the market relationships. If the market relationships break down, they can't get fixed by themselves.

All transactions that take place in a market are governed by a set of contractual relations. The political nature of these contracts is demonstrated by the exchange of information and the bargaining and negotiations between agents. The contracts usually are driven by conflicting objectives of different partners. These 'conflicts' are reconciled by the ultimate sharing of the 
benefits from the transaction. Negotiations give little scope for autonomous actors, as they require compromise with the individual interpretation of what is fair and intrinsically good.

The role of government has to be brought to the centre of debates on ethical regulation of efficient markets, and on coordination and governance of economic activities based on morally sound principles. The Chinese Government, for example, identifies five leading roles for itself: 1 . promoter of growth, 2. manager of the economy, 3. distributor of income, 4. regulator of industry, and 5. protector of citizen and business (Liou, 1998). This by no means contradicts the present role of government in a market economy. The differences are mainly in the means used by government to perform these roles. Such a pragmatic vision of government and markets requires a set of pragmatic rules, negotiated across the spectrum of very different socio-political systems and actors. Kant's transcendental vision of a Categorical Imperative according to which actors unconditionally accept a synthetic apriory proposition as a universal principle to guide their behaviour is difficult to materialise in a socio-political context. Recent events related to the Copenhagen agreement on climate change demonstrate that even when there is a common vision on morally sound objectives, there are fundamental differences on how to pursue them, constraining actors. Constrained actors are not capable to make free choices and hence a Federated World Order has to accommodate practical reasoning in a world of inequalities.

\section{References}

Beetham, D. (1987) Bureaucracy. Open University Press, Milton Keynes.

Bendor, J. (1990) Formal models of bureaucracy: A review. In N. B. Lynn and A. Wildavsky (Eds.), Public administration: The state of the discipline (pp. 373-417). Chatham, NJ: Chatham House.

Breitenbach, H., Burden, T., Coates, D. (1990) Features of a Viable Socialism. Harvester Wheatsheaf, Brighton.

Coase, R. (1937) The Nature of The Firm, In: Economica, No. 4, pp. 386-405.

Daley, Dennis M. (1998) The decline and fall of the Roman Empire: Lessons on management, International Journal of Public Administration, 21:1, pp. 127-143.

Frances, J. et. al., (1991) Introduction, In: Markets, Hierarchies and Networks: The Co-ordination of Social Life, Ed. by Thompson, G. et. al, pp. 1-20, Sage Publ., London.

Frantz, Janet E. (1997) The high cost of policy termination, International Journal of Public Administration, 20:12, pp. 2097-2119.

Greenwood, Justin (1997) The succession of policy termination, International Journal of Public Administration, 20:12, pp. 2121-2150 
Harmon, Michael M. (1998) Decisionism and Action: Changing perspectives in organization theory, International Journal of Public Administration, 21:6-8, pp. 819-838.

Harvey, B. (1996) "Mastering Management: Corporate Governance and Non-exec", In: Financial Times, May 03, (1764), p. 10.

Hayek, F. (1944) The Road to Serfdom. London: Routledge and Kegan Paul.

Hill, J. (1985) Why so much stability? The role of agency determined stability? The role of agency determined stability. Public Choice, 46, 275-287.

Kant, Immanuel (1788) Critique of Practical Reason, 2002 Edition, Translated by Werner Pluhar, Hackett Publishing Co.

Kant, Immanuel (1785) Grounding for Metaphysics of Morals, 1981 Second Edition, Translated by James Ellington, Hackett Publishing Co.

Kant, Immanuel (1797) Metaphysics of Morals, 1996 Edition, Cambridge University Press.

Kant, Immanuel (1795) On Perpetual Peace, 2005 Edition, Cosimo, Inc.

Katzell, R. A., and Thompson, D. E. (1990) Work motivation: Theory and practice. American Psychologist, 45, 144-153.

Knott, J. H., and Miller, G. J. (1987) Reforming bureaucracy: The politics of institutional choice. Englewood Cliffs, NJ: Prentice Hall.

Kornai, J. (1992) The Socialist System: The Political Economy of Socialism. Oxford: Clarendon Press.

Krugman, P. (2009) How Did Economists Get It So Wrong?, The New York Times, September 6, 2009

LaPorte, T. R. (1971) The recovery of relevance in the study of public organization. In F Marini (Ed.), Toward a new public administration: The Minnowbrook perspective pp. 17-47. Scranton, PA: Chandler.

Levacic, R. (1991) "Markets: Introduction", In: Markets, Hierarchies and Networks: The Coordination of Social Life, Ed. by Thompson, G. et. al, pp. 21-23, Sage Publ., London.

Liou, Kuotsai Tom (1998) The role of government in economic development: The Chinese experience, International Journal of Public Administration, 21:9, pp. 1257-1283.

McGuinness, T. (1991) "Markets and Managerial Hierarchies", In: Markets, Hierarchies and Networks: The Co-ordination of Social Life, Ed. by Thompson, G. et. al, Sage Publ., London.

McNutt, P. (2002) Economics of Public Choice, Edward Elgar.

Mintzberg, H. (1983) Power In and Around Organisations. Prentice-Hall, Englewood Cliffs, N. J.

Mueller, D. (2003) Public Choice, Cambridge University Press.

Ouchi, W. (1991) "Markets, Bureaucracies and Clans", In: Markets, Hierarchies and Networks: The Co-ordination of Social Life, Ed. by Thompson, G. et. al, pp. 246-255, Sage Publ., London.

Rainey, H. G. (1993) Work motivation. In R. T. Golembiewski (Ed.), Handbook of Organization Behavior, pp. 19-39. New York: Marcel Dekker.

Russell, Gregory and Waste, Robert (1998) "The limits of reinventing government", American Review of Public Administration, 28:4, pp. 325-346

Selden, Sally, Brewer, Gene and Brudney, Jeffrey (1999) The role of city managers: Are they principals, agents, or both?, American Review of Public Administration, Jun 1999, 29:2, pp. 124-148

Thompson, G. Frances, J., Levacic, R., Mitchell, J. (eds) (1991) Markets, Hierarchies and Networks: The Co-ordination of Social Life, Sage Publ., London. 
Todeva, E. (1998) The Transformation of the Socialist Governance System, South Bank European Papers 6-98, London.

Todeva, E. (2005) "Governance, control and coordination in network context: the cases of Japanese Keiretsu and Sogo Sosha", Journal of International Management, vol.11, no.1, pp. 87-109

Todeva, E. (2006) Business Networks: Strategy \& Structure, New York: Taylor \& Francis.

Wamsley, G. L. (1990) Introduction. In G. L. Wamsley, R. N. Bacher, C. T. Goodsell, P. Kronenberg, J. A. Rohr, C. M. Stivers, O. F. White, and J. F. Wolf (Eds.), Refounding Public Administration. Newbury Park, CA: Sage.

Weber, Max (1978) Economy and Society. An Outline of Interpretative Sociology. Collection edited by G. Roth, University of California Press.

Williamson, O. (1975) Markets and Hierarchies: Analysis and Antitrust Implications. Free Press, New York.

Williamson, O. (1981) "The Economics of Organisations: The Transaction Cost Approach", In: American Journal of Sociology, No. 87, pp. 548-577.

Williamson, O. (1985) The Economic Institutions of Capitalism. Free Press, New York.

Wilson, W. (1987) The study of Administration. Political Science Quarterly, 2,197-222. 